\title{
Reliability of Third Molar Development for Age Estimation in Gujarati Population: A Comparative Study
}

Neha Gandhi ${ }^{1^{*}}$, Sandeep Jain ${ }^{2}$, Manish Kumar ${ }^{3}$, Pratik Rupakar ${ }^{4}$, Kanaram Choyal ${ }^{5}$ and Seema Prajapati ${ }^{6}$

${ }^{1}$ Department of Oral Pathology and Microbiology, Pacific Dental College and Hospital, Debari, India

${ }^{2}$ Department of Community Dentistry, Pacific Dental College and Hospital, Pacific Academy of Higher Education and Research (PAHER) University, Debari, Udaipur, Rajasthan, India

${ }^{3}$ Department of Oral Pathology, MMCDSR Mullana, Ambala, India

${ }^{4}$ Department of Dentistry, G.M.E.R.S. medical college, Sola, Ahmedabad, Gujarat, India

${ }^{5}$ Dental Officer, Field Hospital, Asian Productivity Organization (APO), West Bengal, India,

${ }^{6}$ Department of Oral Pathology, Govt. Dental College and Hospital, Ahmedabad, Gujarat, India

*Corresponding author: Neha Gandhi, Department of Oral Pathology Pacific Dental College and Hospital, Debari, Udaipur - 313 001, Rajasthan, India, Tel: +919784943920; E-mail: drnehagandhi9@gmail.com

Received date: Jun 25, 2014, Accepted date: Sep 23, 2014, Publication date: Sep 26, 2014

Copyright: (C) 2014 Gandhi N, et al. This is an open-access article distributed under the terms of the Creative Commons Attribution License, which permits unrestricted use, distribution, and reproduction in any medium, provided the original author and source are credited.

\begin{abstract}
Background: Age assessment may be a crucial step in postmortem profiling leading to confirmative identification. In children, Demirjian's method based on eight developmental stages was developed to determine maturity scores as a function of age and polynomial functions to determine age as a function of score. Aim: Of this study was to evaluate the reliability of age estimation using Demirjian's eight teeth method following the French maturity scores and Indian-specific formula from developmental stages of third molar with the help of orthopantomograms using the Demirjian method.
\end{abstract}

Materials and Methods: Dental panoramic tomograms from 30 subjects each of known chronological age and sex were collected and were evaluated according to Demirjian's criteria. Age calculations were performed using Demirjian's formula and Indian formula. Statistical analysis used was chi-square test and ANOVA test and the Pvalues obtained were statistically significant. Results: There was an average underestimation of age with both Indian and Demirjian's formulas. The mean absolute error was lower using Indian formula hence it can be applied for age estimation in present Gujarati population. Also, females were ahead of achieving dental maturity than males thus completion of dental development is attained earlier in females. Conclusion: Greater accuracy can be obtained if population-specific formulas considering the ethnic and environmental variation are derived performing the regression analysis.

Keywords: Chronological age; Demirjian's method; Dental maturity; Panoramic radiographs; Polynomial functions; Regression analysis; Third molar

\section{Introduction}

Forensis" means "before the forum." Forensic sciences play an important role in age determination, when individuals without valid documentation of their age are involved in criminal or immigration investigations and for clinicians to know the variations in degree of maturation [1]. Saunders, a dentist, was the first to publish information regarding dental implications in age assessment by presenting a pamphlet entitled "Teeth A Test of Age" to the English parliament in 1837 [2].

In the current scenario, most of the age estimation modalities are invasive, requiring lengthy processing times, use of expensive instruments and the services of an experienced pathologist to deduce the age of the person. It is in this juncture that the branch of radiology comes handy as it offers an insight into the developmental stages of the teeth, which provides a baseline data for age estimation in children and adolescents [3]. The application of radiology in forensic sciences was introduced in 1896, just 1 year after the discovery of the X-ray by
Roentgen, to demonstrate the presence of lead bullets inside the head of a victim [2].

Developing teeth are used most reliably in age estimation; teeth are the most indestructible part of the body and exhibit the least turnover of natural structure. They therefore not only survive death but also remain relatively unchanged thereafter for many thousands of years [2]. The anticipated developmental sequence that human dentition follows to reach complete dental development can be utilized for age determination process. The methods based on the stages of tooth formation as appreciated on radiographs seem to be more appropriate in the assessment of age than those based on skeletal development as the dental development and calcification is controlled more by genes than by environmental factors [2].

Among the radiographic methods, evaluation of third molar maturity is likely to be the best age estimation method as it is noninvasive, and usable dental images are easily obtained whereas many of the skeletal aging indicators cannot be evaluated radiographically. Estimation of age in children by assessing the dentition is considered more reasonable because the dental development and calcification status is more genetically dependent and relatively free of environmental change [4]. Various studies have 
been carried out by several authors on children and adolescents of different geographic and ethnic origins for age estimation using Demirjian's method but there are relatively few studies in context to Indian population including the present population of Indian subcontinent. Thus, the purpose of the present study is to evaluate the reliability of this method for age estimation in present population and hence the role of third molar in age estimation.

\section{Materials and Methods}

In this study dental panoramic tomograms from 30 subjects of known chronological age and sex were collected from Department of Orthodontics, Ahmedabad, Gujarat, who came for seeking orthodontic treatment. The age range was $10-30$ years and subjects were divided into five age groups as follow: 10.1-15, $15.120,20.1-25$, 25.1-30 years.

The rationale for dividing the orthodontic sample based on sex was that the maturity score assigned to each tooth based on its developmental stages was gender specific due to the differing rates in the development of the teeth in the either sex. Within each sex sample was divided into four subgroups to assess the reliability of third molar in age estimation since it is only the third molar which is still developing under normal conditions [3]. The panoramic radiographs were used because they are easier to make than intraoral radiographs in young or nervous children; they give less radiation to full mouth radiograph. The picture of mandibular region they produce is little distorted, but this is not serious drawback, because our rating system is based on shape criteria and relative values rather than on absolute lengths [6].

The inclusion criteria were healthy children and adolescent of 1030 years, full complement of teeth in mandibular left or right side [3]. The exclusion criteria were history of systemic disease that could affect the presence and development of wisdom tooth, history of serious illness or dental trauma and who had undergone any orthodontic treatment or permanent tooth extraction, mandibular hypodontia because Demirjian's method could not be applied for subjects with any of missing left mandibular teeth, low-quality radiographs and image deformity affecting third molar visualization and distortion and crowding of teeth where the root structure of the teeth could not be clearly discernible $[3,7,8]$.

The original Demirjian's method was based on eight calcification stages that represent the crown and root calcification up to the apex closure for the seven left permanent mandibular teeth. In the modified method third molar was added, which increased the possibility of prediction until 18 years and more. So in the present study Demirjian's modified method was used. Orthopantomograms (OPGs) were evaluated for the developmental stages of all eight teeth present in mandibular left quadrant from A to $\mathrm{H}$ as described by Demirjian et al. Each tooth was given a stage according to the modified Demirjian method. To construct mathematical models, each stage of the eight teeth was given a gender-specific biologically weighted score, as given by Demirjian et al [4].

Stage A: Cusp tips are mineralized but have not coalesced.

Stage B: Mineralized cusps are united so the matured coronal morphology is well defined.

Stage C: The crown is about half formed and the pulp chamber is evident and dentinal deposition is occurring.
Stage D: Crown formation is complete to the dentinoenamel junction. The crown is about half formed and the pulp chamber is trapezoidal form.

Stage E: Formation of the inter-radicular bifurcation has begun. Root length is less than the crown length.

Stage F: Root length is at least as great as crown length. Roots have funnel-shaped endings.

Stage G: Root walls are parallel, but apices remain open.

Stage H: Apical ends of the roots are completely closed, and the periodontal membrane has a uniform width around the root.

Demirjian et al. [6] recommended that their maturity scoring system is valid measuring instrument for universal use because according to them it is reasonable to assume that the pattern of development of the teeth will not very much different in different populations, so the maturity scores will be similar in different populations. The differences will arise only when these are converted to dental ages, for which regression analysis was performed for each of the populations [6]. So in the present study Demirjian's maturity scores were used for different stages of eight teeth separately for males and females. The sum of the score for each tooth is a dental maturity score rescaled linearly to 100 . This score is converted into dental age using the regression formulas with age as a function of maturity score as derived by Demirjian et al. for French-Canadian population and Acharya et al. for Indian population $[4,6,9]$.

If a tooth is missing on the left side, Demirjian recommended the use of a homologous or contralateral tooth. But if a tooth is missing bilaterally, Demirjian's method cannot calculate a maturity score and hence age.

The formulas used in the present study are as follows:

Demirjian's formula [4]

Equation 1:

Males: Age $=\left(0.000055 x S^{3}\right)-\left(0.0095 x S^{2}\right)+(0.6479 x S)-8.4583$

Females: Age $=\left(0.0000615 \mathrm{xS}^{3}\right)-\left(0.0106 \mathrm{xS}^{2}\right)+(0.6997 \mathrm{xS})-9.3178$

Indian-specific formula (Acharya): [9]

Equation 2:

Males: Age $=27.4351-\left(0.0097 \mathrm{xS}^{2}\right)+\left(0.000089 \mathrm{xS}^{3}\right)$

Females: Age $=23.7288-\left(0.0088 \mathrm{xS}^{2}\right)+\left(0.000085 \mathrm{xS}^{3}\right)$

The assessment of different formation stages was completed on the ordinal scale. Formulas for age estimation used in this study were those derived by Demirjian et al., for France population (Equation 1), and the Indian-specific formula (Equation 2) derived by Acharya et al., using the polynomial regression analysis. The mean and standard deviation of chronological age, estimated age, differences between the two were calculated. Comparisons between the estimated ages derived by the two formulas and between genders were obtained using the chisquare test, ANOVA and Pearson's correlation coefficient. The statistical level of significance was chosen at $\mathrm{P}<0.05$. Accuracy and reliability of these formulas for age estimation in the present population were compared. The accuracy is symbolized by the mean differences between the estimated age and the real age. All statistical analyses were performed using SPSS, 12.0 statistical software programs. 
Citation: Gandhi N, Jain S, Kumar M, Rupakar P, Choyal K, et al. (2014) Reliability of Third Molar Development for Age Estimation in Gujarati Population: A Comparative Study. J Forensic Res 5: 1000242. doi:10.4172/2157-7145.1000242

Page 3 of 6

\section{Results}

The study group comprised of 30 subjects, with 7 (23.33\%) males and $23(76.66 \%)$ females. 10 subjects were between 10.1 and 15 years of age of which $1(10 \%)$ was male and $9(90 \%)$ were females, 18 subjects were between 15.1 and 20 years of age of which 5 (27.78\%) were males and $13(72.22 \%)$ were females, 1 female was in $20.1-25$ years and 1 male was in 25.1-30 years [Table 1].

A comparison between chronological age and estimated age derived by Indian formula and Demirjian's formula showed that the Mean Absolute Error (MAE) calculated by Indian formula for the above age groups was $1.10 \pm 1.106,0.44 \pm 0.987,-1.18$ and -6.73 , respectively, which was statistically significant $(P<0.0001)$. And the MAE calculated by Demirjian's formula for the above age groups was -0.55 $\pm 0.672,-2.58 \pm 0.987,-4.99$ and -9.84 , respectively, which was also statistically significant $(\mathrm{P}<0.0001)$. But the mean error by Indian formula (0.37) was much less than that of MAE by Demirjian's formula $(-2.22)$ [Table 2].

\begin{tabular}{|l|l|l|l|}
\hline Age Group & Males & Females & Total \\
\hline $10.1-15$ & 1 & 9 & 10 \\
\hline $15.1-20$ & 5 & 13 & 18 \\
\hline $20.1-25$ & 0 & 1 & 1 \\
\hline $25.1-30$ & 1 & 0 & 1 \\
\hline
\end{tabular}

Table 1: Distribution of subjects according to age and sex.

\begin{tabular}{|l|l|l|l|l|l|l|}
\hline Age Group & Subjects (30) & $\begin{array}{l}\text { Mean Chronologic } \\
\text { Age } \pm \text { SD }\end{array}$ & $\begin{array}{l}\text { Mean Estimated } \\
\text { Age In Indian } \\
\text { Formula } \pm \text { SD }\end{array}$ & $\begin{array}{l}\text { Mean Estimated Age } \\
\text { by } \\
\text { Formula } \pm \text { SD }\end{array}$ & $\begin{array}{l}\text { Difference in Estimated } \\
\text { Age and Chronological } \\
\text { Age by Indian Formula }\end{array}$ & $\begin{array}{l}\text { Difference in Estimated } \\
\text { Age and Chronological } \\
\text { Age } \\
\text { Formula } \\
\text { Demirjian }\end{array}$ \\
\hline $10.1-15$ & 10 & $13.20 \pm 0.815$ & $14.31 \pm 1.25$ & $12.66 \pm 0.692$ & $1.10 \pm 1.106$ & $-0.55 \pm 0.672$ \\
\hline $15.1-20$ & 18 & $17.12 \pm 0.527$ & $17.56 \pm 1.41$ & $14.54 \pm 0.836$ & $0.44 \pm 0.987$ & $-2.58 \pm 0.987$ \\
\hline $20.1-25$ & 1 & 20.25 & 19.07 & 15.26 & -1.18 & -4.99 \\
\hline $25.1-30$ & 1 & 26.17 & 19.44 & 16.33 & -6.73 & -9.84 \\
\hline P value & & & $<0.0001$ & $<0.0001$ & $<0.0001$ & $<0.0001$ \\
\hline
\end{tabular}

Table 2: Comparison between chronological age and estimated age derived by Indian formula and Demirjian's formula in the orthodontic group.

Thus, both Indian and Demirjian formulas can be used for age estimation in 10.1-20 years age group with greater effectiveness of Indian formula than Demirjian's formula.

A comparison of error of age estimation by Indian formula and Demirjian's formula in males and females showed that the MAE calculated by Indian formula in males was $-0.65 \pm 2.745$ and in females was $0.68 \pm 1.189$. The MAE calculated by Demirjian's formula in males was $-2.90 \pm 3.205$ and in females was $-2.02 \pm 1.519$, which was statistically significant $(\mathrm{P}=0.011)$ [Table 3$]$.

\begin{tabular}{|l|l|l|l|l|}
\hline \multirow{2}{*}{ Stage of Development of Third Molar } & \multicolumn{2}{l|}{ Males (7) } & \multicolumn{2}{l|}{ Females (23) } \\
\cline { 2 - 6 } & No. & Mean Age \pm SD & No. & Mean Age \pm SD \\
\hline C & 1 & 13.5767 & 6 & 13.3911 \\
\hline D & 1 & 15.1526 & 10 & 14.9903 \\
\hline E & 4 & 17.505 & 1 & 18.4644 \\
\hline F & 0 & & 3 & 18.5009 \\
\hline G & 0 & & 2 & 19.5197 \\
\hline H & 1 & 26.17 & 1 & 19.4276 \\
\hline
\end{tabular}

Table 3: Comparison of error of age estimation by Indian formula and Demirjian's formula in males and females of the orthodontic group.

Thus, Indian formula was more reliable for age estimation with only slight underestimation ( -0.65 years) in males and overestimation (0.68 years) in females with $\mathrm{P}=0.071$. Demirjian's formula is less reliable as it gave a considerable difference in age, with underestimation in both males and females of approximately 2-3 years.
Mean chronological age and standard deviation for the mineralization stages of mandibular third molar in males and females showed that dental development was almost parallel in males and females from 13 to 15 years. Stage $\mathrm{H}$ was attained earlier in females suggesting that completion of development of third molar was earlier in females than in males [Table 4]. 


\begin{tabular}{|l|l|l|l|l|l|l|}
\hline Sex & Subjects (30) & $\begin{array}{l}\text { Mean Chronological } \\
\text { Age }\end{array}$ & $\begin{array}{l}\text { Mean Estimated Age } \\
\text { by Indian Formula } \pm \\
\text { SD }\end{array}$ & $\begin{array}{l}\text { Mean Estimated } \\
\text { Age by Demirjian } \\
\text { Formula } \pm \text { SD }\end{array}$ & $\begin{array}{l}\text { Mean Absolute Error } \\
\pm \text { SD by Indian } \\
\text { Formula }\end{array}$ & $\begin{array}{l}\text { Mean } \\
\text { Error } \begin{array}{c}\text { Absolute } \\
\text { Demirjian Formula }\end{array}\end{array}$ \\
\hline Males & 7 & $17.84 \pm 4.018$ & $17.19 \pm 1.836$ & $14.94 \pm 0.947$ & $-0.65 \pm 2.745$ & $-2.90 \pm 3.205$ \\
\hline Females & 23 & $15.72 \pm 2.57$ & $16.41 \pm 2.214$ & $13.71 \pm 1.223$ & $0.68 \pm 1.189$ & $-2.02 \pm 1.519$ \\
\hline P value & & 0.405 & 0.021 & 0.071 & 0.011 \\
\hline
\end{tabular}

Table 4: Mean and standard deviation for the mineralization stages of mandibular third molar in males and females in the orthodontic group.

\section{Discussion}

Tooth formation is suitable for estimation of age because it is a continuous, progressive process that can be followed radiographically from the crypt stage to the closure of root apex [7]. And once a tooth is fully mineralized and erupted, it forms a relatively stable entity rendering it strong tissue in the body and resistant to post-mortem destruction. Hence, it can be a reliable indicator of individual's age in archaeological and forensic contexts, regarding age estimation in children and adults.

In this context third molars offer a unique advantage over other teeth because its development is continuous over longer period and until a later age [7]. Age estimation in prenatal, neonatal and early postnatal child makes use of histological (up to 12 weeks of utero) and radiological methods (which indicates mineralization patterns), thus playing an important role in legal implications associated with feticide and infanticide [2].

Age estimation in children and adolescents makes use of two important factors, namely tooth eruption and tooth calcification. Both morphological (visual assessment of tooth's emergence status) and radiological methods have been instrumented in determining age in this category. Various methods applied are as follows: Schour and Masseler method; Moorees, Fanning and Hunt method; Demirjian, Goldstein and Tanner method; Nolla's method and age estimation using open apices, Demirjian's method being most commonly used. Thus, playing an important role in legal implications associated with juvenile legislation $[2,11]$.

The method most frequently used in forensic dentistry for children and adolescents was described by Demirjian et al. [6], based on eight calcification stages that represent the crown and root calcification to the apex closure for the seven left permanent mandibular teeth $[8,12]$. Demirjian and Goldstein [6] have excluded the third molar because this tooth is often extracted and is the tooth with greatest variability in development and eruption [4]. But for age prediction all the variables are important, and for dental maturity the third molar is the only one giving a prediction past 16 years of age $[4,9,10]$. A drawback of original method was that it excluded the third molar owing to its tendency to be congenitally missing and also because of wide variation in in its development $[4,6]$. Nevertheless, this tooth is one of the few predictors available for the assessment of age in the 16-23 year age group and, hence, third molar was added to broaden the applicability of the original method up to the age of 18-23 years. Thus, root maturity in the third molar may be one marker that indicates an individual is at least 18 years of age. The third molar development is complete at 2425 years of age hence this method could not be applied for age estimation into higher age groups $[4,9,10]$.
In the present study the radiographic method as described by Demirjian et al. was used with the aim of age estimation in 10 to 30 years of age groups. This method of age estimation is population specific therefore polynomial equations derived for Indian population by various authors were used for age calculations and comparison was made with the ages derived from the original formulas $[4,6,9,10,12]$.

The effectiveness of age prediction is usually represented by the MAE, which is calculated as the difference between the estimated age and the actual age at the time of exposure. In age estimation studies, MAE is considered as a standard measure to estimate the effectiveness of the methods. The smaller the MAE, the greater is the accuracy $[9,10]$.

For the radiographic methods of age estimation, the number of estimates that fell in the error group of $< \pm 1$ year, within $1.1-2$ years, and $> \pm 2$ years give the estimate of the accuracy. Errors of $< \pm 1$ have been considered by some authors (Ritz-Timme S., Mornstad H.) as "good results," hence in this study, estimates with such errors have been categorized as "accurate." $[2,8]$ Concurrently, errors of $> \pm 2$ years have been designated as "inaccurate," because such differences are unacceptable in forensic age prediction of young individuals.

Thirty subjects of the orthodontic group ranged between 10 and 30 years, with $23(76.66 \%)$ females and $7(23.33 \%)$ males. The age limit was based on the fact that development of third molar is complete at this age.

In the present study, the comparison between chronological age and estimated age derived by Indian formula and Demirjian's formula in the orthodontic group showed that Indian formula can be used for age estimation in present population with 10.1-20 years age, with slight

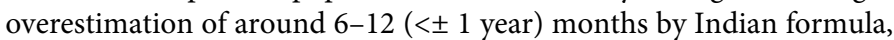
which is "acceptable" in accordance with Acharya [9]. When Indianspecific formula as derived by Acharya was applied for this population, $60 \%$ (18 out of 30 ) subjects were within \pm 1 year of actual age, $36.6 \%$ (11 out of 30 ) subjects were with \pm 2 years and remaining $4 \%$ were $> \pm$ 2 years. This discrepancy may be due to the fact that dental development is complete by about 20 years in males and 21 years in females, due to wide variation in population of Indian sub-continent. The error could be lower if the age range of the present population sample was younger than 22 years [1].

The MAEs were lower in the younger age group, indicating that the presence of third molar is only in 16.1 to 23 year old individuals, which results in greater inaccuracy in age estimation, which was in accordance with Acharya and Kumar [9,3]. Moreover, beyond the age of 21 years, the MAE had risen considerably to 5-6 years where the number of samples where only two. The reason attributed is due to the completion of third molar development and the paucity of samples. This finding was also in accordance with Kumar and Gopal [3]. 
There was an average underestimation of age when Demirjian's formula was used. This was in accordance with Acharya [9]. Our findings were in contrast to various studies (Wahrekar et al.; Koshy; Prabhakar $[17,14,21]$ carried out on Indian population, where an average overestimation was observed. The reason for this difference may be due to difference in the environmental factors, such as the socioeconomic status, nutrition and dietary habits that vary in different population groups [12-17]. AM Warhekar mentioned that malnutrition can have an adverse effect on the dental and skeletal maturation [17]. Underestimation of age was higher when Demirjian's formula was used. The possible explanation for the difference in the estimated dental age between the French-Canadian children and the present population can be attributed to the difference in ethnicity and/or considerable time gap between two studies on the dental development of these children.

Thus, by comparing the values of MAEs by both the formulas, it can be concluded that Indian formula can be used for age estimation in present population but there is a need to develop population-specific formulas by performing regression analysis to overcome the error, where in the total maturity score obtained for each individual (based on maturity scores given by Chaillet and Demirjian for French Canadian population) was entered as the independent variable and the corresponding age as the dependent variable [5].

On comparing the error of age estimation by Indian formula and Demirjian's formula in males and females in the orthodontic group showed that age prediction by Indian formula was better in males than in females with the MAE of 0.65 in males compared to MAE of 0.7 in females. This was in contrast with the studies carried out by Acharya and Kumar[7], where the age estimation was better in females.

Demirjian's formula is less reliable as it gave a considerable difference in age, with significant $(\mathrm{P}<0.0001)$ underestimation in both males and females of approximately $2-3$ years. This was in accordance with Acharya [9].

The comparison of mineralization stages of third molar in males and females in the orthodontic group showed that the mean age of attainment of stage $\mathrm{C}$ and $\mathrm{D}$ was delayed in males than females which revealed that females were in advancement of dental maturity than males in lower age groups (10-20 years). For stage E, delay in females was observed which was statistically insignificant $(\mathrm{P}=0.823)$. Studies carried out by various authors on various populations of different ethnic origin suggested that the average age of attainment of stage $\mathrm{C}$ in males was 14.8 years and in females was 14.7 years; stage D in males was attained at 15.5 years and in females at 15.4 years; stage $\mathrm{E}$ at around 16.0 years in males and 16.5 years in females; stage $\mathrm{F}$ at 18.1 years in males and 18.9 years in females; stage $G$ at 19.84 years in males and 20.2 years in females; stage $\mathrm{H}$ at 21.97 years in males and 21.88 years in females. Our findings were in accordance with Karatas et al., who suggested that all the mean ages of attainment of tooth development are earlier in females as compared to males [18]. In the present study also girls completed the root formation (stage $\mathrm{H}$ ) earlier than boys showing sexual dimorphism during mineralization of mandibular third molars, as in accordance with Verma et al. [7]. According to our data for stages $\mathrm{C}$ and D, around $69 \%$ females and $29 \%$ males were $\leq 15$ years old. For stage $\mathrm{E}$ around $57 \%$ males and $5 \%$ females were $\leq 18$ years old. For stage $\mathrm{H}$ around $14 \%$ males and $5 \%$ females were $>20$ years. This was in accordance with findings of Sisman et al., Arany et al., and other workers who carried out studies on German, Spanish, South African and Turkish populations [10,19].
From the results of this study it can be concluded that third molar development being a good indicator for age estimation of younger age group below 30 years.

\section{Summary and Conclusion}

There was an average underestimation of age in the present population by both Indian formula and Demirjian's formula with a higher underestimation with Demirjian's formula. An average underestimation of age was found in both males and females by both the formulas but the error was low with Indian formula. Females were ahead of dental maturity than males suggesting that completion of dental (third molar) development is attained earlier in females.

Thus, Indian formula can be applied for age estimation but greater accuracy can be obtained if population-specific formulas considering the ethnic and environmental variation are derived performing the regression analysis.

\section{Acknowledgement}

I would like to thank my mentor, Dr. Jyoti G. Chawda (Professor \& Head, Oral Pathology Department, Government Dental College \& Hospital, Ahmedabad) for her guidance and support.

\section{References:}

1. Solari AC, Abramovitch K (2002) The accuracy and precision of third molar development as an indicator of chronological age in Hispanics. J Forensic Sci 47: 531-535.

2. Panchbhai AS (2011) Dental radiographic indicators, a key to age estimation. Dentomaxillofac Radiol 40: 199-212.

3. Kumar VJ, Gopal KS (2011) Reliability of age estimation using Demirjian's 8 teeth method and India specific formula. J Forensic Dent Sci 3: 19-22.

4. Chaillet N, Willems G, Demirjian A (2004) Dental maturity in Belgian children using Demirjian's method and polynomial functions: new standard curves for forensic and clinical use. J Forensic Odontostomatol 22: 18-27.

5. Chaillet N, Demirjian A (2004) Dental maturity in South France: A comparison between Demirjian's method and polynomial functions. J Forensic Sci 49: 1059-1066.

6. Demirjian A, Goldstein H, Tanner JM (1973) A new system of dental age assessment. Hum Biol 45: 211-227.

7. Verma P, Sachdeo J, Gupta VK, Datt GS, Guruprasad R (2011) Age estimation of adolescents and young adults based on development of mandibular third molars: A panoramic study. J Indian Acad Oral Med Radiol 23: 9-13.

8. Galic I, Nakaš E, Prohic S, Selimovic E, Obradovic B, Petrovecki M (2010) Dental age estimation among children aged 5-14 years using the Demirjian method in Bosnia-Herzegovina. Acta Stomatol Croat 44: 17-25.

9. Acharya AB (2011) Age estimation in Indians using Demirjian's 8-teeth method. J Forensic Sci 56: 124-127.

10. Arany S1, Iino M, Yoshioka N (2004) Radiographic survey of third molar development in relation to chronological age among Japanese juveniles. J Forensic Sci 49: 534-538.

11. Rajendran R (2009) Shafer's Textbook of Oral Pathology. Elsevier India 21: 883-885.

12. Chaillet N, Nyström M, Kataja M, Demirjian A (2004) Dental maturity curves in Finnish children: Demirjian's method revisited and polynomial functions for age estimation. J Forensic Sci 49: 1324-1331. 
Citation: Gandhi N, Jain S, Kumar M, Rupakar P, Choyal K, et al. (2014) Reliability of Third Molar Development for Age Estimation in Gujarati Population: A Comparative Study. J Forensic Res 5: 1000242. doi:10.4172/2157-7145.1000242

Page 6 of 6

13. Davis PJ, Hägg U (1994) The accuracy and precision of the "Demirjian system" when used for age determination in Chinese children. Swed Dent J 18: 113-116.

14. Koshy S, Tandon S (1998) Dental age assessment: the applicability of Demirjian's method in south Indian children. Forensic Sci Int 94: 73-85.

15. Nykänen R, Espeland L, Kvaal SI, Krogstad O (1998) Validity of the Demirjian method for dental age estimation when applied to Norwegian children. Acta Odontol Scand 56: 238-244.

16. Willems G, Van Olmen A, Spiessens B, Carels C (2001) Dental age estimation in Belgian children: Demirjian's technique revisited. J Forensic Sci 46: 893-895.

17. Warhekar AM, Wanjari PV, Phulambrikar T (2011) Correlation of radiographic and chronological age in human by using Demirjian's method: A radiographic study. J Indian Acad Oral Med Radiol 23: 1-4.
18. Karatas OH, Öztürk F, Dedeoglu N, Çolak C, Altun O (2012) Dental age assessment: The applicability of Demirjian method in southwestern of eastern Anatolia region Turkish children. Cumhuriyet Dent J 15: 130-137.

19. Sisman Y, Uysal T, Yagmur F, Ramoglu SI (2007) Third-molar development in relation to chronologic age in Turkish children and young adults. Angle Orthod 77: 1040-1045.

20. Darji JA, Govekar G, Kalele SD, Hariyani H (2011) Age estimation from third molar development: A radiological study. J Indian Acad Forensic Med 33: 130-134.

21. Prabhakar AR, Panda AK, Raju OS (2002) Applicability of Demirjian's method of age assessment in children of Davangere. J Indian Soc Pedod Prev Dent 20: 54-62. 